\title{
Editorial: Zero Energy Mass Custom Home (ZEMCH)
}

John K. Calautit BEng (Hons), PhD, CEng, MIMechE Assistant Professor, University of Nottingham, Nottingham, UK

This themed issue includes selected papers from the proceedings of the fourth international conference on the Zero Energy Mass Custom Home (ZEMCH) network, which was held in vibrant city of Lecce, Italy from 22 to 25 September 2015 and was organised by the University of Salento in partnership with The British University in Dubai and University of Trento. ZEMCH aims to tackle issues arising in the delivery of socially, economically and environmentally sustainable built environments in developed and developing countries, which accommodate people with different socio-economic backgrounds, ages and abilities.

Annually, the conference brings together researchers and government and industry professionals to discuss the problems and delights of design, manufacturing and marketing surrounding the delivery of low-carbon dioxide and, ultimately, zero-energy houses that are customisable on a mass scale, either built or under construction in developing and developed countries.

The ZEMCH network was established in 2010 after a number of international industry-academia collaborative study tours were organised in order to observe the state-of-the-art production and sales facilities of leading low- to zero-energy or carbon dioxide emission sustainable housing manufacturers in Japan, which also practise inclusive design. Presently, the ZEMCH network consists of 667 global partners from academia, industry and government based in over 45 countries.

Built upon the success of previous conferences, the fourth conference in the ZEMCH series attracted a large number of submissions from all around the world, which were subjected to a two-stage peer review process. With the objective of producing a high-quality conference, papers were selected for presentation at the conference and publication in the proceedings. The scope of the conference is extensive and 64 oral presentations were delivered.

Extended and revised versions of the top articles, which were selected by the ZEMCH scientific committee and the Engineering Sustainability editorial panel, are included in this themed issue to disseminate further the leading research in this field first presented at ZEMCH 2015. The selected papers cover key research topics in the areas of sustainable built environments, including green building rating systems, intelligent building technologies, gamification in the built environment, four-dimensional (4D) building information modelling (BIM), vertical green walls and building-integrated photovoltaics (BIPV).
Haşim Altan DipArch, MArch, PhD, RIBA, CEng, MCIBSE, PGCE, FHEA Associate Professor, Department of Architecture Engineering, University of Sharjah, Sharjah, UAE

A wide range of 'green' building rating and assessment tools are used around the world to help mitigate the environmental impacts of the built environment through the measurement and recognition of sustainability performance (AlWaer and Kirk, 2012; Haroglu, 2013). Sustainability is now a top priority in the Middle East region and countries like Jordan, Qatar and UAE have developed their own green building rating system to incorporate social, economic, environmental and cultural aspects in modern construction. The first article in this issue (Shareed and Altan, 2017) assessed and compared the different building sustainability rating systems in the Middle East with well-established and leading international green building certification systems such as the Building Research Establishment Environmental Assessment Method (Breeam) and Leadership in Energy and Environmental Design (Leed). The assessment focused on the vision and structure, categories, weightings, levels and certification processes. The study highlighted the importance of developing and employing local green building codes or systems to achieve sustainability targets according to national priorities and regulations.

The second article in this issue (Gadakari et al., 2017) focused on finding the relationship between building intelligence and sustainability by developing a predictive statistical model that can estimate the impact of intelligent building technologies (IBTs) on sustainability scores of green building rating tools. The data were collected from 40 Breeam- and Leed-certified buildings in the UK and Europe and were subjected to qualitative and quantitative analysis methods. The work highlighted the numerous benefits that IBTs can provide, and the analysis proved that there was a strong positive correlation between the number of IBTs used in a building and the scores achieved.

One of the most important challenges faced by the building sector today is tackling the 'energy performance gap', which is the disparity in energy use of buildings, from predicted performance at the design stage to actual performance in use (Baborska-Narozny and Stevenson, 2017; Johnston et al., 2015; Robinson et al., 2016). The third paper in this issue (Patlakas and Raslan, 2017) discusses the significant role of building users in determining the energy use of buildings and the influence of their behaviour on the 'performance gap'. The authors attempted to addressed the issue by using 'gamification' or game-based tools to help users better understand the issues relating to building performance, post-occupancy evaluation surveys and facilities management. The study demonstrated both the advantages and challenges of gamification which were in agreement with the experiences reported in the literature. 
Editorial: Zero Energy Mass Custom

Home (ZEMCH)

Calautit and Altan
Retrofitting of existing buildings offers significant opportunities for reducing global energy consumption and emissions (McGrath et al., 2013). Retrofit projects present many challenges for managers and decision makers, particularly when the end users remain in the building over the period when the works are carried out and are disrupted by the retrofit process. The fourth article (Chaves et al., 2017) discusses the potential of using 4D BIM to support better planning of construction works and reduced disruption to end users in retrofit projects while delivering energy-oriented and cost-effective solutions. The work developed recommendations detailing the steps to be undertaken by decision makers in evaluating retrofit scenarios in situations where the dwellings are in use during the retrofit works.

During the last decade, the presence of green walls or vertical gardens in building designs has increased, providing several benefits to the urban environment including reduced energy demands of the buildings' cooling systems, mitigation of the heat island effect and improvement of the thermal performance of buildings (Coma et al., 2017). The fifth article in this issue (Vox et al., 2017) carried out field tests to investigate the effects of two types of green vertical passive systems on building walls in the Mediterranean region. Several climatic parameters concerning the walls and the ambient conditions were analysed to estimate the variations in the surface temperature of walls equipped with the greenery systems. The effective thermal resistance of the green layer was evaluated as a useful tool for models in order to estimate internal climate and energy fluxes.

During the last 15 years, double-skin facades (DSFs) have become an increasing and vital element in the built environment, particularly in combination with integrated photovoltaic (PV) panels. By simultaneously functioning as envelope material and power generator, building integrated photovoltaic (BIPV) systems can be more costeffective and can provide savings in materials and energy costs, reduce carbon dioxide emissions and add architectural enhancement to the building (Agathokleous and Kalogirou, 2016). The final article (Yu et al., 2017) investigated and compared the energy and thermal performance of a building with a glass DSF and a PV-integrated DSF through dynamic simulation modelling. The results showed that the PV-DSF system was advantageous during summer to decrease cooling load. The building energy consumption of the PV-DSF decreased by $15 \%$ compared with the glass DSF. Furthermore, $1438 \mathrm{kWh}$ of electricity was generated, which corresponded to about $18 \%$ of the annual building energy consumption required.

This themed issue disseminates up-to-date research on sustainable built environments and I hope you are inspired by the articles to contribute new knowledge in the field.

On behalf of the ZEMCH Chairs and Organising committee, I would like to thank all the authors, speakers and delegates for their contributions and support to the ZEMCH conference. Thanks to the members of the International Programme Committee who have done an excellent job of providing their reviews of the papers, ensuring appropriate quality. Many thanks also to the reviewers for their suggestions which have improved the quality of the articles presented in this themed issue. I would also like to take this opportunity to invite you to the upcoming ZEMCH 2018 conference which will be held in Melbourne, Australia from 29 January to 1 February 2018.

\section{REFERENCES}

Agathokleous RA and Kalogirou SA (2016) Double skin facades (DSF) and building integrated photovoltaics (BIPV): a review of configurations and heat transfer characteristics. Renewable Energy 89: 743-756.

AIWaer H and Kirk D (2012) Building sustainability assessment methods. Proceedings of the Institution of Civil Engineers - Engineering Sustainability 165(4): 241-253, http://dx.doi.org/10.1680/ ensu.10.00058.

Baborska-Narozny M and Stevenson F (2017) Mechanical ventilation in housing: understanding in-use issues. Proceedings of the Institution of Civil Engineers - Engineering Sustainability 170(1): 33-46, http:// dx.doi.org/10.1680/jensu.15.00053.

Chaves FJ, Tzortzopoulos P, Formoso CT and Biotto CN (2017) Building information modelling to cut disruption in housing retrofit. Proceedings of the Institution of Civil Engineers - Engineering Sustainability 170(6): 322-333, http://dx.doi.org/10.1680/ jensu.16.00063.

Coma J, Pérez G, de Gracia A et al. (2017) Vertical greenery systems for energy savings in buildings: a comparative study between green walls and green facades. Building and Environment 111: 228-237.

Gadakari T, Hadjri K and Mushatat S (2017) Relationship between building intelligence and sustainability. Proceedings of the Institution of Civil Engineers - Engineering Sustainability 170(6): 294-307, http://dx.doi.org/10.1680/jensu.16.00028.

Haroglu $\mathrm{H}$ (2013) The impact of Breeam on the design of buildings. Proceedings of the Institution of Civil Engineers - Engineering Sustainability 166(1): 11-19, http://dx.doi.org/10.1680/ensu.11.00030.

Johnston D, Miles-Shenton D, Farmer D and Brooke-Peat M (2015) Postconstruction thermal testing: some recent measurements. Proceedings of the Institution of Civil Engineers - Engineering Sustainability 168(3): 131-139, http://dx.doi.org/10.1680/ensu.14.00048.

McGrath T, Nanukuttan S, Owens K, Basheer M and Keig P (2013) Retrofit versus new-build house using life-cycle assessment. Proceedings of the Institution of Civil Engineers - Engineering Sustainability 166(3): 122-137, http://dx.doi.org/10.1680/ ensu.11.00026.

Patlakas P and Raslan R (2017) A computer game to help people understand the energy performance of buildings. Proceedings of the Institution of Civil Engineers - Engineering Sustainability 170(6): 308-321, http://dx.doi.org/10.1680/jensu.16.00024.

Robinson JF, Foxon TJ and Taylor PG (2016) Performance gap analysis case study of a non-domestic building. Proceedings of the Institution of Civil Engineers - Engineering Sustainability 169(1): 31-38, http:// dx.doi.org/10.1680/ensu.14.00055.

Shareef SL and Altan H (2017) Building sustainability rating systems in the Middle East. Proceedings of the Institution of Civil Engineers - Engineering Sustainability 170(6): 283-293, http://dx.doi. org/10.1680/jensu.16.00035.

Vox G, Blanco I, Fuina S et al. (2017) Evaluation of wall surface temperatures in green facades. Proceedings of the Institution of Civil Engineers - Engineering Sustainability 170(6): 334-344, http://dx.doi. org/10.1680/jensu.16.00019.

Yu J, Kim J, Kim S and Kim J (2017) Thermal and energy performance of a building with PV-applied double-skin façade. Proceedings of the Institution of Civil Engineers - Engineering Sustainability 170(6): 345-353, http://dx.doi.org/10.1680/jensu.16.00017. 